\title{
Patterns as a paradigm for theory in community-based learning
}

John M. Carroll • Umer Farooq

\begin{abstract}
Learning about information technology is typically not a first-order goal for community-based volunteer organizations. Nonetheless, information technology is vital to such groups for member recruiting and management, communication and visibility to the community, and for primary group activities. During the past 12 years, we have worked with community groups in Centre County, Pennsylvania, and Montgomery County, Virginia. We have built partnerships with these groups to better understand and address their learning challenges with respect to information technology. In this paper, we suggest that patterns, standard solution schemata for recurring problems (as used in architecture and software engineering, among other design domains), can be a paradigm for codifying and developing an understanding of learning in and by community organizations. Patterns are middle-level abstractions; they capture regularities of practices in ways that are potentially intelligible, verifiable, and perhaps useful to the practitioners themselves. We present two example patterns and discuss issues and directions for developing patterns as a theoretical foundation for community-based learning.
\end{abstract} 11

Keywords Community informatics · Community-based learning · Design · Informal

J. M. Carroll · U. Farooq

Center for Human-Computer Interaction and College of Information Sciences and Technology,

The Pennsylvania State University, University Park, PA 16803, USA

U. Farooq

e-mail: ufarooq@ist.psu.edu

J. M. Carroll ( $\square)$

College of Information Sciences and Technology, The Pennsylvania State University,

307 H IST Building, University Park, PA 16803, USA

e-mail: jcarroll@ist.psu.edu 


\section{Introduction}

Most adult learning occurs in informal contexts, that is, contexts outside educational programs. People learn through recreational, civic, and work activities from and/or with their peers. During the past 12 years, we have been studying informal learning about information technology (IT) as it occurs in communities and community groups (e.g., Carroll \& Rosson, 1996, 2003). Informal learning about IT is a pervasive challenge in modern society. Many recreational, learning, and work activities require at least some IT skill, and this is becoming more pervasive. While some business and governmental organizations make use of formal IT training programs, much of this learning occurs informally.

Community groups provide an interesting arena for informal IT learning. Such groups have very distinctive resources and constraints. On the one hand, they are social linchpins of our communities and our society. Community-based groups are everywhere, in every community; the majority of people belong to at least one such organization (Kavanaugh, Reese, Carroll, \& Rosson, 2005). Churches, service organizations, arts and cultural groups, clubs and recreational groups are bastions against the "decline of community," as described by Bellah, Madsen, Sullivan, Swindler, and Tipton (1986) and by Putnam (2000), among others. They are in fact a fast-growing and increasingly important category of organization. In the state of Pennsylvania, USA, where our current research site is located, there are 700,000 non-profit organizations, compared to only 12,500 in 1940. Non-profit organizations, which are largely community based and rely heavily on volunteer labor, now account for about $10 \%$ of total employment in the state (Grobman, 2002).

On the other hand, community groups are under funded and under staffed to cope with the complexity and the rate of change in information technology. Maintaining PCs, networks, and software, perhaps servers, and obtaining or otherwise organizing personnel support - including support for training and learning - is expensive, both financially and with respect to organizational capacity. Community groups lack material resources of all sorts (money, skills, telecommunication infrastructure), as well as organizational structures, protocols, and continuity to effectively cope with technology. Relying on volunteers to organize, manage, and carry out most vital organizational activities, including learning about technology, entrains knowledge-management risks. Volunteers come and go, often taking with them organizationally vital knowledge and skill (Farooq et al., 2007).

In this paper, we reflect on a set of participatory action research partnerships we built with various community-based groups to better understand and address their learning challenges with respect to information technology. In other papers, we have described various aspects of these partnerships, and the organizational learning we facilitated and observed (Carroll, Chin, Rosson, \& Neale, 2000; Farooq et al., 2005; Merkel et al., 2004; Merkel et al., 2005). Our specific concern in this paper is to develop a model for codifyingand reusing problems and solutions across varied contexts. This is the practical sense in which we invoke the sometimes-problematic term "theory" in the title of this paper.

We suggest that patterns, standard solution schemata for recurring problems - used in architecture and software engineering, among other design domains - can be a paradigm for developing a theory of community-based IT learning. Patterns, in this sense, consist of a problem, a description of the problem's context, an analysis of relevant forces (that is, resources and trends that enable or constrain possible solutions to the problem), a statement of a solution to the problem, a discussion of how the resulting context was changed by the solution, and examples of the solution (pointers to instantiations of the pattern in our ongoing work). 
Patterns are a good example of what C. Wright Mills (1959) famously called "middlelevel abstractions." They capture regularities of practices in ways that are potentially intelligible, verifiable, and perhaps useful to the practitioners themselves. For example, among Alexander's (Alexander et al., 1977) patterns is the Street Café pattern. The problem this pattern addresses is the need to enhance feelings of openness and access to people and activity in city spaces. The context is tightly packed, tall buildings and narrow streets, with many people anonymously hurrying along. The forces are construction and operation costs, the hassles of getting municipal approvals to open a café onto the sidewalk, the personal approach-avoidances of making eye contact and meeting others in public, and so forth. Documenting and analyzing the pattern provides a resource to designers and other design stakeholders for sharing and improving solutions.

In the balance of this paper, we discuss two key patterns of community-based learning: Informal developmental learning and Scaffolded documentation. Informal development learning is a solution to the problem of paralyzing lack of control over IT. Scaffolded documentation is a solution to the problem of knowledge loss through turnover in volunteers. Both of these are truly common problems for contemporary community-based groups. The solutions are authentic-we have observed them-but they cannot be claimed to be typical. In that sense, we are proactively tailoring the concept of pattern for participatory action research, extending its somewhat anthropological conception: "standard solution to a recurring problem," to that of a program for social intervention: "potentially effective solution to a crippling problem." The notion of pattern we are exploring here is similar to what has been called "emerging pattern" (Chung et al., 2004) or "pre-pattern" (Saponas, Prabaker, Abowd, \& Landay, 2006).

This more activist interpretation of patterns is highly consistent with the developing methodological vision of pattern languages in computer-supported cooperative work (CSCW), computer-supported collaborative learning (CSCL), and community informatics (Avgeriou, Papasalorous, Retalis, \& Skordalakis, 2003; Erickson, 2000; Goodyear et al., 2004; Schuler, 2002). Indeed, the intelligibility of patterns to the people whose practice is described by the patterns, and the use of patterns as self-regulatory social mechanisms, is an important direction in this work that we return to in the discussion.

\section{Informal developmental learning}

Many community groups are paralyzed in a sense with respect to information technology. They are dissatisfied with some or perhaps all of their IT applications - their Web-pages, databases, newsletter publishing, and so forth. But they cannot articulate a plan to address these problems.

Not so many years ago, it was a radical proposition to assert that community organizations could maintain information and manage activities through the Internet. Through the 1980s, community groups used the Internet to facilitate information dissemination, discussion, and joint activity pertaining to municipal government, public schools, civic groups, local events, community issues and concerns, and regional economic development and social services. Some of these projects have become touchstones of Internet activism - jobs, housing, and veterans' issues in the Berkeley Community Memory (Farrington \& Pine, 1997), community health in the Cleveland Free Net (Beamish, 1995), problems of the homeless in the Santa 
Monica Public Electronic Network (Rogers, Collins-Jarvis, \& Schmitz, 1994), and public education and Native American culture in the Big Sky Telegraph (Uncapher, 1999).

In their decade, these projects were the leading edge of community networking. But in fact they were implemented on relatively simple networking software platforms - the file transfer protocol (ftp). People were inspired to be able to use this new medium to exchange civic information and perspectives with fellow citizens. But of course the broader context was that most civic and community-based organizations, and indeed most commercial and governmental organizations as well, were still operating in a world of typewriters and telephones.

Today, baseline expectations throughout western society about communication are different. One expects to be able to identify and access an organization's URL (universal resource locator). One expects to be able to send or receive an email announcing a meeting. The pervasive adoption of email and the WWW present opportunities and challenges to community-based volunteer organizations. The opportunities are obvious: Organizations can get their message out for "free," Web communication may result in more time-efficient management of work, and so on.

The challenges are less obvious. The Web is easy and accessible to all, if accessibility means browsing. But when a community organization wants to post and serve current information about activities and new programs, it faces a host of issues-Who will design and create the Website, the various pages, and the content in the pages? Who will maintain the site and contents, run the Web server, and update software? It is likely that no one in the organization has these skills. If so, it is unlikely that anyone wants to invest much time and effort into acquiring these skills.

The problem we are addressing is that community-based volunteer organizations experience a lack of control over their own IT. What makes the problem worse is that these organizations can have so little in-house expertise that they are not even able to recognize the extent to which they lack control, or to diagnose how they might begin to remedy the situation. An example from our own fieldwork was an environmental group who felt they were participating in IT activities over which they had control, because they had hired a commercial vendor to produce their website. Indeed, when they wished to change the Website design, they discovered that this outsourcing had deprived them of control. The vendor had all the knowledge, all the content, and all the code (Farooq et al., 2005). Hence, part of the problematic lack of control over IT is not realizing that this problem exists in the first place.

A key context for the challenges that community-based organizations face with respect to control of their own IT is the rapid and pervasive growth of computing and the Internet during the past two decades. The WWW began as a way for elite military and academic groups to exchange information, but it has evolved rapidly into a powerful information source for ordinary citizens.

Our empirical work takes place in North America, chiefly in Pennsylvania and Virginia in the United States. Sixty-three percent of American adults now use the Internet. Since 2000 , the distribution of Internet users across gender, income, and race is surprisingly regular. Use of the Internet has become normal in daily life. On a typical day in 2004, 70 million adult Americans logged on to the Internet (about 35\%), up from about 50 million in 2000. Fifty-eight million used email; 35 million got news; 24 million did job-related research; 24 million looked for political information. Ninety-four million Americans have used the Internet to find or to share health-related information; 97 million Americans have 
used government Websites. Sixty-five percent of American Internet users believe that the Internet has helped their relationships with friends; $56 \%$ believe it has helped their relationships with their own family members. Sixty million American homes now have broadband Internet access, compared with 6 million in 2000. (All data are from Rainie \& Horrigan, 2005.)

These facts and trends contrast interestingly with trends relating to the ability and interests of Americans in preparing for more active roles with respect to IT. For example, undergraduate enrollments in computer science fell about 25\% between 2000 and 2003 (Computer Research Association, 2003).

Moreover, as the Web has evolved, browsing, searching, and carrying out purchases has become easier and more accessible, while creating dynamic, interactive Web content has become increasingly more difficult, requiring server-based mechanisms (e.g., servers that support web-based discussion forums), embedded components written in other programming languages (e.g., Java applets, ActiveX controls, Flash, or JavaScript), or plug-ins that augment the user's browser and allow it to receive data in closed, proprietary formats. These advances create richer experiences for the passive information consumer on the Web, but they add technical obstacles for users interested in constructing novel, interactive functionality to their own creations.

Two key forces shaping the solution to the problem in this pattern are the lack of resources among volunteer community-based groups and the important role such groups play in social capital formation.

Community volunteer organizations generally lack financial resources, telecommunications infrastructure (high-bandwidth connectivity), equipment, skills, and access to training. They lack almost every relevant resource to support an IT strategy. In our studies, we have found that it is typical for community organizations to have no budget line item for technology. In one case, a community organization we worked with only had Internet access via the home connections of its members; the organization as such had no connectivity other than its own phone line. Lack of resources is a force - it affects how community volunteer organizations will address the problem of having less control of their IT.

Lack of relevant resources is exacerbated by the fact that IT is generally not a core concern of these organizations. Not surprisingly, a local historical society is chiefly concerned with preservation of sites and artifacts, informal education programs, and interactions with school and community groups. Even though an outside consultant might conclude that IT is a key to addressing their primary concerns in an efficient and effective manner, they do not necessarily see it that way.

Social capital is the generalized trust, social interaction, and mutual reciprocity throughout a group, a community, or a society (Coleman, 1990). Because community volunteer organizations depend upon intrinsic motivation and personal commitment, rather than material rewards, social capital formation and preservation is especially critical to their survival and growth (King, 2004). And the social capital produced through participation in these organizations is critical to the whole society (Putnam, 2000).

Indeed, many studies of contemporary American society have concluded that traditional mechanisms of social capital formation in American communities are in decline (e.g., Bellah et al., 1986; Putnam, 2000). For example, between the 1960s and the 1990s, participation rates in a variety of civic activities declined: Red Cross volunteering declined by $60 \%$; participation in parent-teacher organizations declined by nearly half, membership 
in the League of Women Voters and in the Jaycees both declined by $40 \%$; the number of people reporting that they attended a public meeting on town or school affairs in the past year has declined by more than a third; volunteering of Boy Scout troop leaders declined by a quarter; voter turnout in national elections declined by nearly a quarter; churchgoing and church-related activities declined by a sixth; the proportion of Americans who socialize with neighbors more than once a year declined by nearly a sixth.

In this societal context, the formation and preservation of social capital through participation in community groups has become of greater importance to the larger society.

An important alternative to formal pedagogy is learning informally. Informal learning refers to learning that occurs outside of classrooms, schools, and other formal instructional environments and activities, and it includes incidental, self-directed, and lifelong learning. People with existing and active commitments to their communities may find it more meaningful to learn about Web programming, for example, by helping to create a Web application for a community service organization than by attending an intensive programming class. What we know about adult learners suggests that this would indeed be the case (e.g., Knowles, 1973).

In fact, informal learning represents an important part of the common culture of the Internet and its democratic and community roots (Rheingold, 1993). Informal learning of Web technologies often involves "learning by doing"; for example, learning in the course of downloading and exploring new software, posting on newsgroups, getting product technical support, or copying and editing useful or appealing Web pages. Such activities are often situated in "authentic" tasks, providing solutions to real, concrete problems that the learner faces either as an individual or as part of a group or community.

One solution to the problem of lack of control over IT is a self-sustained process of informal learning, in which organizations identify and analyze their technology needs, and then learn about IT through continuing engagement in solving their own problems. We describe this solution as comprising three facets: reflection, analysis, and enactment (see Fig. 1). Reflection is a self-assessment on part of the community organization of its relationship to its own IT. It is more effective to come to the realization that there is a lack of control on one's own than to be told there is a problem by another. Technology self-assessments and discussions of critical incidents within the organization are good approaches for this reflection. In the example we discussed above, when the environmental group wanted to change their Website and found that this would be a long and difficult process, they realized that they were not in control to the extent they wanted and needed to be.

Organizational competition with peer groups may also prompt reflection, such as multiple environmental organizations in a proximate community competing for project or operations funding from one government source.

The second facet is identification and analysis of organizational practices, needs, and issues related to IT. Community-based volunteer organizations are unique in that their work activities may be loosely coupled and minimally coordinated (Carroll, 2001). They depend primarily on volunteerism, they face a lack of financial and temporal resources, and so forth, which makes them unique. Technology needs and issues must be identified and analyzed in context of these unique structural features of community-based volunteer organizations. While technology provides many opportunities for these organizations to achieve their civic-oriented goals, community-based volunteer organizations still face formidable challenges in sustaining the use of technology (Merkel et al., 2005). Part of the 
Context: American society and the Internet

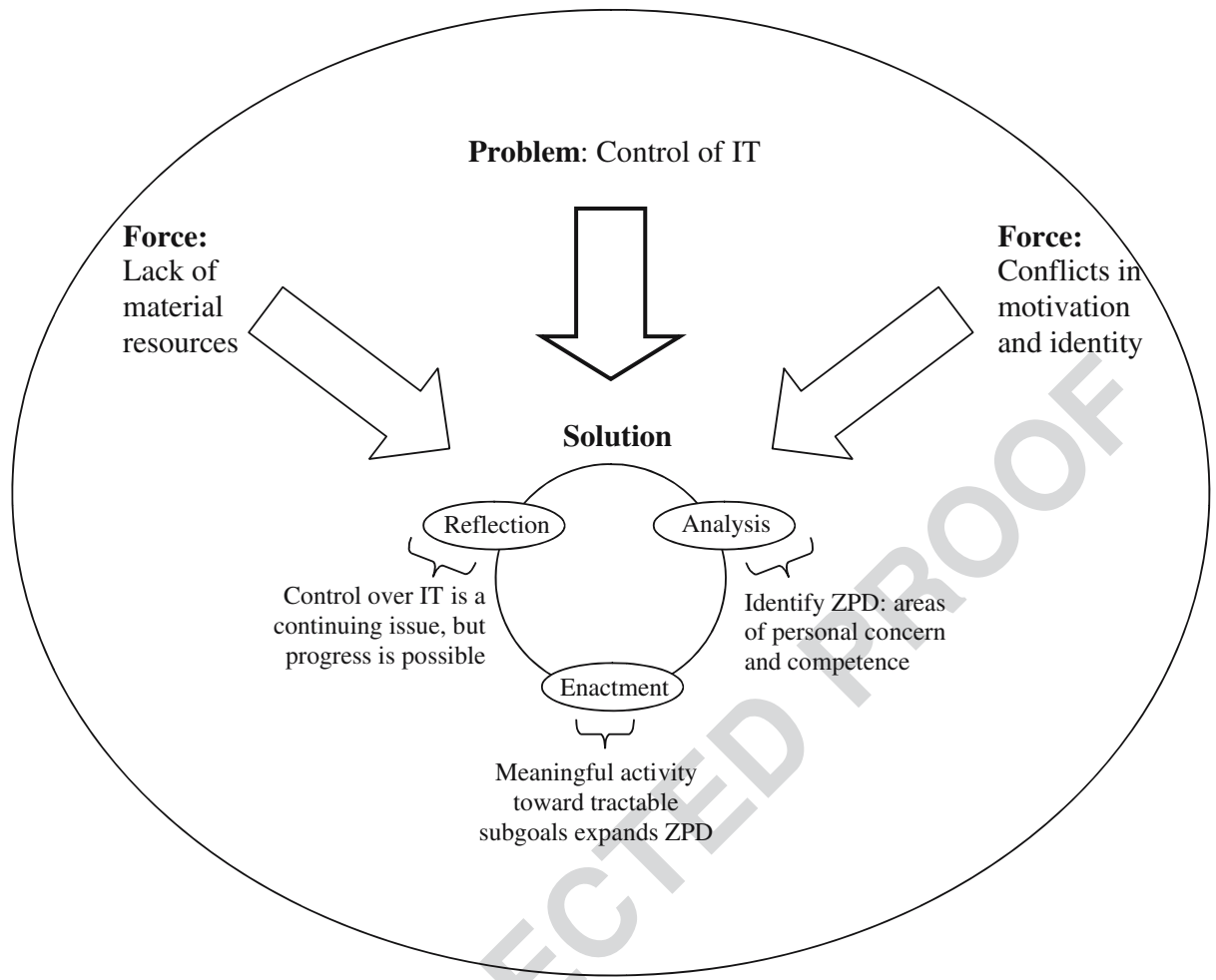

Resulting Context: Sustainable/expanding control over own IT

Fig. 1 Schema for informal development learning pattern

reason is that the adoption and use of technology is not aligned with their unique structure. Hence, these organizations must identify and analyze their organizational practices to see how IT can become a part of their organizational day-to-day activities. One way to achieve this is to develop technology plans by assessing the current status of work practices and technology-related activities in the organization (e.g., Techsoup, 2005).

The third facet of our pattern solution is enactment. The solution must be assimilated into everyday practices of the organization. In other words, learning about IT is an on-going facet of everyday activity, in the sense that Dewey (1916) described traditional models for situated learning as integrated into community activities, and in the sense that Lave and Wenger (1991) describe learning as the process of becoming a full participant in a sociocultural practice. Enactment makes the solution sustainable (e.g., Merkel et al., 2005).

The three facets are not stages. They are three aspects of the solution that can be discussed independently. Reflection, analysis, and enactment are all keys to achieving more control over IT because they are interdependent. A community organization could be engaged in meaningful activities but may not realize that they are not in control of IT, or vice versa. The integration of these facets leveraged through the social mechanisms of the community allows community organizations to inspire and assist one another in learning about, utilizing, and developing skills for advanced IT tools and resources. 
It is difficult to project all the effects of any socio-technical innovation. Two likely consequences of informal developmental learning are the following:

(1) This pattern would help in achieving sustainable learning related to IT. IT is critical for community-based volunteer organizations to achieve their goals for many reasons: it increases their outreach to the larger geographical community, workload may be lightened by email and web-based communication, and it may provide more convenience for interested stakeholders through features like online donations. However, with the fast-paced change in IT, these organizations have to continuously learn. Our pattern assigns sustainability a key role in the solution by emphasizing the need for continuous engagement in meaningful activities over time.

(2) This pattern would help to recast organizational practices related to IT. In our pattern solution, community-based volunteer organizations are cognizant of the fact that sustainable use of technology is key to their long-term success. Decision makers in such organizations make decisions by following a reflexive and proactive process of thinking about how particular technology-related decisions will affect the organizational goals and use of that technology in the near and far future. Part of this process involves perceiving how technology learning will be managed in their organization over time (e.g., Who will update the site when you are on vacation? Who will maintain the site if you, your technology person, or a volunteer leaves the organization?) and how will a long-term technology plan be incorporated as organizational practice (e.g., What will happen to the site when the grant runs out? Who is going to add content to these more dynamic features of the site?).

These consequences are some of the major ones that result from following our pattern solution. They all converge toward greater control over IT for community-based volunteer organizations. We now discuss our pattern solution with two examples that also illustrate some of the resulting context.

The informal developmental learning pattern can be illustrated in many communityoriented participatory action research (PAR) projects. Spring Creek Watershed Community (Spring Creek, http://www.springcreekwatershed.org) is a sustainable development, volunteer organization committed to regional environmental and economic planning, specifically, planning by watershed area rather than by individual municipalities. The organization works to explain this vision to the larger community and to show how watersheds have an impact on quality of life and the local economy. We worked with this organization for approximately 14 months (Merkel et al., 2004).

A major technology issue that Spring Creek faced was to redesign their website. Before our involvement with the organization, Spring Creek hired a commercial vendor to develop and maintain their website. Spring Creek was dissatisfied with the website because it did not reflect their mission, overall goals, or the fact that they were a local organization concerned with environmental and economic planning. For example, whereas the goal of Spring Creek was local economic planning, influencing decision makers, and encouraging quality of life through watersheds, the website depicted them as a generic tree-hugger group. Moreover, the vendor resisted any major restructuring of the website and often times used his/her sole control over the community organization's technology to avoid changes. 
Critical incidents such as this forced Spring Creek to realize the problem. By delegating their website design and maintenance to a commercial vendor, Spring Creek lacked control of IT because they were not active participants in website related activities.

To address this problem, key stakeholders in Spring Creek first analyzed the situation. This was achieved by holding a kickoff meeting, initiated by the Spring Creek lead coordinator, in which many volunteers from Spring Creek's social network were involved. The result of this meeting was that Spring Creek would itself redesign their website so that they retained control over its management. The volunteers who attended this first meeting formed, by default, an informal technology committee that would deliberate over subsequent meetings to see Spring Creek's vision through.

During the website redesign process, committee members had different perspectives on "design" that created tension between technical requirements and the need to organize information on the website effectively. One of the more technical volunteers wanted to follow a rapid prototype approach by proposing several new designs for the website, whereas another volunteer who had been working previously with Spring Creek suggested that content design should be done first. The latter proposal meant that layout design would be done afterwards - this would allow Spring Creek to focus on the organizational message they want to convey through their website. Key stakeholders in Spring Creek agreed to the latter idea by being active participants in this negotiation process, trying to tease out the pros and cons of the different proposals put forward. This resulted in the creation of an expert-novice zone of proximal development that concretely led to achieving common ground and understanding through hierarchical modes of learning (Farooq et al., 2005).

One way that key stakeholders from Spring Creek became active participants in the social context of the website-redesign process was through the use of scenarios as conceptual tools (Farooq et al., 2005). The lead coordinator used scenarios to convey her input into the design process. Active engagement through scenarios had a direct effect in eliciting design, communicating design rationale, and resolving design conflicts. It also had an indirect effect by resulting in increased learning on part of the key stakeholders as they were now transitioning from legitimate peripheral participants to more core actors in the redesign process (Lave \& Wenger, 1991).

The solutions adopted by Spring Creek had both short- and long-term implications. In the short-term, the current stakeholders in Spring Creek's website have become more technology literate. For example, before, one of the key stakeholders did not even know what HTML denoted, and now, after having engaged meaningfully in technology-related activities, is heavily involved in technical discussion forums and basic HTML coding. In the long-term, this solution will result in more autonomy over time, where learning is being captured and transformed into organizational expertise. Some evidence of this is currently being seen. For example, Spring Creek has incorporated technology-related knowledge management practices within the organization and has thus reduced the dependence on outside technical experts. Spring Creek now keeps a documented record of all their website management activities, so that newer volunteers can come in and learn how website maintenance and update is done. Another example of this pattern is described in Carroll and Farooq (2005).

\section{Scaffolded documentation}

Community non-profits typically rely on volunteer members-even for organizationally critical roles. A positive consequence of this personnel paradigm is that much orga- 
nizational problem solving and learning is intrinsically motivated. A negative consequence is that it is common for volunteers to drop out, often suddenly, in response to exigencies in their lives. As a result, community non-profits are relatively more vulnerable to organizational knowledge losses through turnover than are other organizations.

Financial support and technical expertise are critical factors for organizations in order to effectively integrate information technologies into their daily work process. The problem of technology adoption and integration in community organizations goes beyond getting newer versions of software, better hardware, or obtaining general advice on technology issues like installing new software or creating community webpages. The community organizations need advice and assistance that fit their context, which cannot be provided by a general agency. Also, with limited funding resources, it is often not an option for nonprofit organizations to hire technical consultants for long-term support on technology projects. Community organizations are often forced to grow their own expertise to take on technology projects and manage technical issues in their organizations.

Growing expertise means coming up with sets of strategies to manage the limited resources for technology adoption and integration. One set of strategies tackles the problem of the scarcity of the human resource. Several other studies have discussed the importance of recruiting a stable network of technical expertise into nonprofit organizations (Corder, 2001; Eisinger, 2002). The use of volunteers is part of this broader strategy to develop expertise in the organization and to develop a network of support. Growing expertise in small, nonprofit community organizations implies developing longer-term knowledge management strategies.

The use of volunteers can be a problematic strategy. Volunteers may either not have the required skill set or be more interested in working on the social mission of the organization. In a similar vein, a volunteer may design a system that matches his or her own skill set and experience. Berlinger and Te'eni (1999) noted some of the same tensions when incorporating volunteers into an organization. They found that sometimes volunteers design systems that are idiosyncratic based on his/her knowledge of a particular technology (not necessarily the best solution). They also found that sometimes the advice can be short-sighted, especially if a volunteer is new to the organization or is not familiar with its work practices.

The problem we are addressing is the management of tacit knowledge held by nonorganizational stakeholders (volunteers, part-time staff members, etc). This is a major issue for nonprofit organizations because when they lose a volunteer, they may also lose the only person that held the tacit knowledge required to complete technology work (e.g., the password needed to upload files, the location of files critical to the organization). An example from our fieldwork was a food bank that relied on a volunteer to develop and maintain their web site. After the volunteer left, the organization was unable to retain any knowledge of their web site, including trivial information such as the user name and password to access their web site domain.

\section{Context: Technology sustainability through participatory design}

A concern with sustainability is prevalent in the participatory design literature (Bødker, Ehn, Sjögren, \& Sundblad, 2000; Clement \& Van den Besselaar, 1993; Kensing \& Blomberg, 1998; Kensing, Simonsen, \& Bødker, 1998; McPhail, Constantino, Bruckmann, 
Barclay, \& Clement, 1998). In the Civic Nexus project, our view of sustainability is tied to approaches that explicitly connect design to learning. Sachs (1995), for example, argued that "technology design should enhance the human capacity of finding problems and solving them."(p. 40) Similarly, Trigg and Bødker (1994) argued that "system development should be organized as a learning process where the participants, collectively and as individuals, improve their ability to understand and manage processes of technological and organizational change" (p. 46) Design should involve finding ways to help users maintain the new competencies that they have gained through the participatory design process (Bødker et al., 2000).

In our fieldwork, sustainability involves finding ways of working with community organizations in ways that gives them greater control over the use of technology in their organization. We think of sustainability as a dynamic multifaceted process in which users learn to apply technology to address challenges and opportunities in their work, taking into account local contingencies. We define technology broadly to include technical innovations (e.g., software, hardware, websites) and shifts in routines, procedures, practices, etc. Users within an organization and the organization itself are involved in a learning trajectory. They are learning to identify ways that technology can enhance their work, marshal resources within their social network to get work done, solve problems that inevitably occur along the way, and attend to the shifts in roles, practices, and process that result from technology adoption.

Part of the value system for community organizations is their consideration for volunteerism. For example, the Johns Hopkins Nonprofit Sector project reported that the number of people working in civil society organizations in the 35 countries they studied exceeds 190 million, which represents over 30 percent of the adult population in these countries (Salamon, Sokolowski, \& List, 2003). Valuing participation by community organizations is relevant to adoption and design of technology because it is likely that volunteers will participate in and manage technology-related activities.

Because technology is typically not part of the core mission for community organizations, the use of a community-based workforce creates tensions as the organizations work to harness a diverse set of skills. Volunteers and staff members possess a diverse set of technology skills, which makes it difficult to prescribe a skill set while still being participative (McPhail et al., 1998). In addition, managing such diverse constituents requires additional articulation work. This is because it involves increased coordination of the cooperative work processes and operationalization of subtasks (Gerson \& Star, 1986; Gross, 1999).

Our solution can be decomposed into three facets, although more fine-grained constructs can be substituted or augmented. These three facets of our solution-lightweight knowledge management-are technology assessment, contingency planning, and lightweight documentation (see Fig. 2).

Technology assessment deals with evaluating needs of community organizations. Community organizations often have ideas about what they would like to do with technology, but they often need a way to make their plans more concrete. A community technology assessment includes, but is not limited to, descriptions of the organization's: a) mission, decision-making structure, stakeholders, and values; b) current technology 
Context: Tensions in civic sector workforce

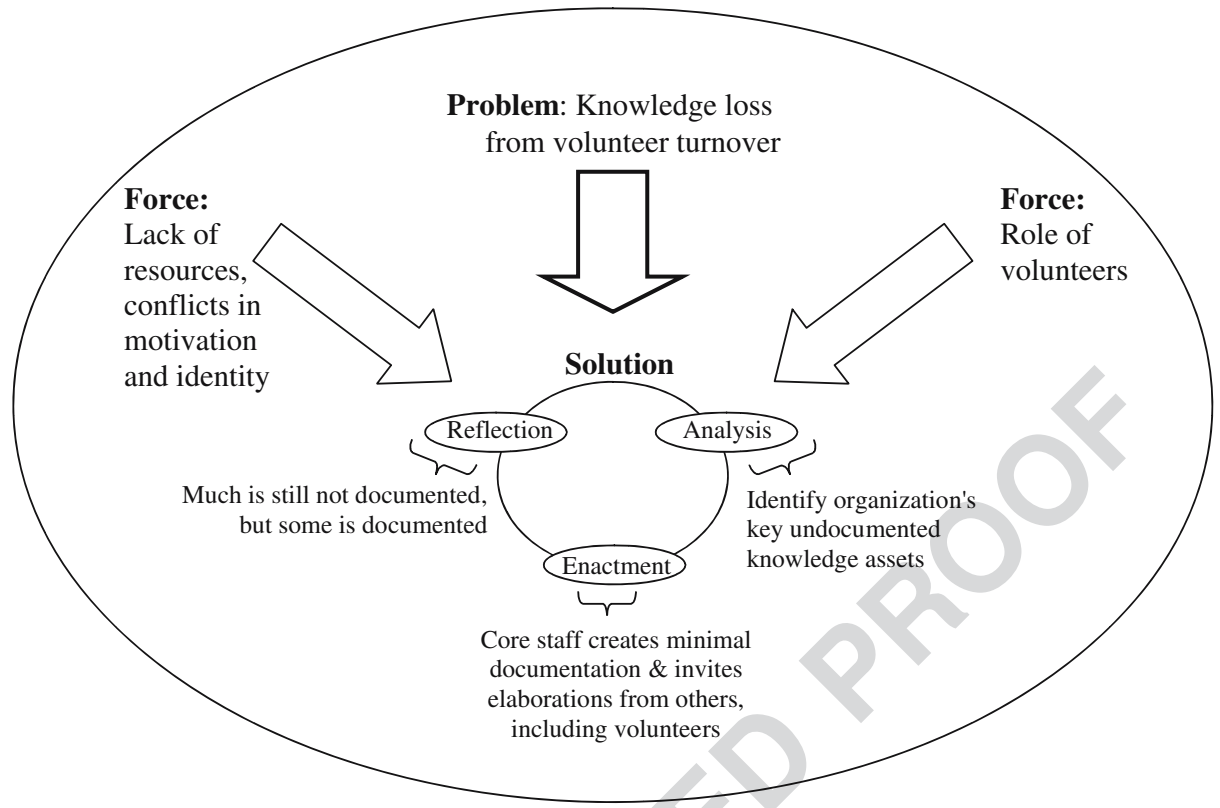

Resulting Context: Sustainable/expanding codification of organizational knowledge

Fig. 2 Schema for scaffolded documentation pattern

infrastructure (e.g., the number and types of computers they have, do they have an organizational website, do they have Internet access); (c) use of technology (e.g., office tasks, information dissemination, commercial or noncommercial pursuits) in decisionmaking and to achieve their communitarian goals; d) human and technical resources that can be leveraged (and that have been used in the past) to work on a technology project; and e) vision for how they would like to use technology if obstacles were removed and a list of potential projects. Our intent in using the technique is to encourage the group to reflect on their current technology needs, prioritize potential technology projects, and assess their resources to get projects done.

The second facet is contingency planning. Part of the work that community groups need to do is to manage the trade-offs involved in managing volunteer labor. A major site of breakdowns for nonprofit organizations is the loss of a volunteer or a staff member who was primarily responsible for some aspect of a technology project. This problem is exacerbated because nonprofits do not have the money to hire a new person to take over these responsibilities. If there is a great deal of turnover, the nonprofit is put in the position of continuously starting over, delaying temporarily and sometimes permanently the achievement of their technology goals. We have addressed the need for long-term planning in our participatory design process by prodding our community partners with questions related to contingency planning. Asking contingency question evokes learning because it helps the organizations make planning more a part of their practice. The organizations learn to ask the kinds of questions that are relevant when initiating and managing technology projects in their organization. They then start asking these questions about other technology projects that they initiate.

459 
The third facet is lightweight documentation. This involves finding a balance between processes that need to be documented and those that do not. Most people do not enjoy the process of documentation even though it plays an important role in managing tacit knowledge within the organization. Documentation evokes sustainability because it is a technique that nonprofits can use to manage knowledge in their organization. Our emphasis on documentation helps to legitimize less formal methods of documentation that people might not recognize as such (e.g. note-taking and "cheat sheets"). These are resources that can be shared with others in the organization and future volunteers. This puts nonprofits more in control of technology in their organization in the sense that they are not continuously starting over every time they lose a staff member or a new volunteer.

Again, with the disclaimer that one can never fully project the effects of any socio-technical innovation, two likely consequences of the scaffolded documentation pattern are:

(1) This pattern would encourage informal learning. The community technology assessment promotes learning because the organizations start to prioritize their current technology needs and the resources that they have available to carry out their technology goals. Asking contingency questions evokes learning because it helps the groups make planning more a part of their practice. The groups learn to ask the kinds of questions that are relevant when initiating and managing technology projects in their organization.

(2) This pattern would enhance organizational preservation of technical expertise. For community-based volunteer organizations, technical experts, just like other volunteers, are temporally volatile. They come, do an IT-related project(s), and go. Since these organizations cannot afford a continual supply of technical experts around the clock, it is natural for these organizations to consider preservation of technical expertise rather than experts. Our pattern solution, in effect, allows community organizations to develop IT-related knowledge management within the organization. Since community organizations would breed their own technical expertise, and would continuously learn and develop their IT skills over time, a culture of eliciting and packaging organizational memory emerges.

An example of this pattern can be illustrated through our yearlong fieldwork with the State College Food Bank (Food Bank). Food Bank is a nonprofit organization that provides emergency food and clothing to those in need. The Food Bank also provides support to a network of other food pantries in the region. The organization has two paid staff members and a steady base of volunteers that serve the organization. They have a Board of Directors that is active in providing oversight for the organization.

One major concern that the Food Bank had when we began to work with them was shortcomings in their technology infrastructure. The staff members wanted to be able to access the Internet at the office and they wanted more control over their organizational website. However, the organization did not yet have Internet access, so when staff members needed to email or access the web, they were forced to do so at home. The management of web resources, including the organization's website, was another major concern. Food Bank relied on a volunteer to update their website. This strategy worked well until the 
volunteer left the organization. As a result, they decided to do this work in-house. This formed the basis of our participatory design work with Food Bank. We helped to train a staff member to take over responsibility for updating and maintaining the website.

As a first step, Food Bank wanted to carry out a technology assessment of their organization in relation to what kinds of resources they needed to get access to high-speed Internet and to maintain their web site in-house. Food Bank relies on volunteer effort in the form of their Board of Directors to address technology infrastructure issues. They used this expertise, for example, to conduct a technology assessment for their organization. A member of the board recommended that they utilize the services of a technology consultant who was a personal acquaintance to evaluate the organization's current technology capacity and to make recommendations for technology upgrades. The assessment that was done served as a roadmap that Food Bank followed to enhance the technical infrastructure of their organization and to make software purchases for the organization. This assessment report also had social implications because it provided evidence that they could use with members of their board to justify technology expenditures.

When the volunteer who was maintaining Food Bank's web site left, they decided to assign responsibility for updating the website to a staff member. We worked with this staff member to teach him how to update and refine Food Bank's web site. Our goal was to work with him in such a way that he was able to transfer his knowledge to others in the organization. This was important because the staff member hoped that eventually he would be able to pass this task on to volunteers who would update the web site from within Food Bank. We consistently encouraged the staff member at Food Bank to document tasks related to the design and update of the web site. The staff member was somewhat resistant to this process. He was a hands-on person preferring to learn by doing the same task two or three times. He once commented "Our intelligence is in our hands," referring to the value of hands-on experience in learning new skills. However, we did realize that after we fade from the setting as researchers, he might forget the knowledge he gained from us. Even worse, if he left the organization, Food Bank would lose this tacit knowledge again. The staff member we worked with was convinced that for operational tasks (e.g., how to add a link to a web page), he was more than capable of retaining such knowledge. However, for higher level and complex tasks, we prompted him to take notes. For example, it was critical to understand the hierarchical structure of the web site in order to add a new web page. He wrote down how the web site was organized, what each of the directories meant, and the associated content of each sub-directory folder. This documentation would be useful as he continued to work on the website, but it will also be useful in the future if someone else takes over this role.

One of our roles in our interaction with Food Bank was to keep this staff member on track with the theme of sustainability when the maintenance of the website is deferred to volunteers. We asked the staff member questions to prod his thinking about the long-term use of volunteers. For example, how long does a particular volunteer plan on working for the organization? What will you do if he/she leaves? How can the work done by one volunteer be transferred to another?

\section{Discussion and programme}

We described and illustrated two patterns from the domain of community-based learning. Informal developmental learning is a specific solution to the recurring problem of lack of control over IT in community volunteer organizations. Scaffolded documentation is a 
solution to the loss of organizational knowledge due to reliance on a volunteering workforce. These patterns closely, and thereby usefully, couple codification and application of design knowledge. This is a highly desirable property in practical design domains like CSCW and CSCL, where many kinds of scientific knowledge necessarily converge and interact (see Carroll \& Rosson, 2003, for general discussion).

The dominant paradigm in community computing is case study research (Yin, 2003). This approach is renowned, of course, for bringing to light important nuances of human behavior and experience, and producing revelatory interpretations. It is regarded as particularly indispensable in the analysis of real-world social systems. However, case study research presents classic challenges with respect to abstraction and generalization. For example, Yin (2003) emphasizes that a theoretical framework for case study research must state conditions under which a particular phenomenon is likely to occur as well as conditions under which it is likely not to occur. The context and forces fields in a pattern schema achieve this. Moreover, case study descriptions, no matter how rich and revelatory, do not provide prescriptive advice. Accordingly, from the standpoint of action research and design, case studies improve our understanding of instances, but do not explicitly guide the creation of new solutions.

Patterns do not replace case studies; they do not provide the vivid narrative view into complex social data. But patterns can complement case studies and provide a theoretical framework for abstracting and generalizing case study descriptions. The two patterns we discussed illustrate this, and the pattern schema we employed to present them indicates how this approach might be extended. Of course, patterns themselves raise many further questions about theory in design and comprise a research programme more than a finished solution (Dearden \& Finlay, 2006). One of the advantages of considering patterns as a paradigm for theory is that design knowledge is codified in self-contained chunks that include descriptions of the domain contexts and recurring problems in those contexts. But in such a programme, what guarantees the coherence and commensurability of the chunks? As an example, suppose we were to go through the effort of creating a more complete pattern language (Alexander, 1979) for community-based learning; what would we have? Is a set of patterns a theory? In the balance of this discussion, we consider the notion of frameworks from software engineering as a direction for further work.

In software engineering, a framework is a reusable design of all or part of a system that is the skeleton of an application customizable by a software developer (Gamma, Helm, Johnson, \& Vlissides, 1994). Frameworks are expressed in a programming language - they are code. A single framework usually contains several to many patterns, and in this sense patterns are narrower than frameworks (Johnson, 1997). Patterns are embodied in and illustrated through their roles in frameworks. Patterns are more abstract, and can be viewed as micro-architectural elements of frameworks. A well-known example in software engineering is the role of the observer, composite, and strategy patterns in the modelview-controller framework (Gamma et al., 1994).

Our concern is how frameworks can be adapted to help guide the instantiation and use of patterns in design and analysis in community-based learning. We believe that frameworks are an important area for further development of patterns as a paradigm for theory in community-based learning.

In the CSCW and CSCL domains of community computing, frameworks are the various types of community networks, community portals, and community organization web sites. For example, the Spring Creek website (discussed earlier) instantiates a design framework: it consists of a shallow information hierarchy navigated by a permanently-displayed dynamic menu that foregrounds a statement of the organization's mission, a rationale, and a 
newsletter archive. The primary graphical content is a set of images depicting typical landmarks throughout the Spring Creek Watershed. This website is literally code, but more specifically it is a code base over which the Spring Creek organization now exerts substantial control. It exemplifies an application skeleton that could be immediately repurposed with a few cut-and-paste operations.

The informal developmental learning and scaffolded documentation design patterns are architectural elements of the Spring Creek website framework; that is, articulating the patterns provides language constructs for design and analysis of websites instantiating this framework. As described earlier, Spring Creek stakeholders became active participants in the website redesign process (informal developmental learning) and later maintained organizational documents that logged their website management activities (scaffolded documentation).

Frameworks are a design nexus for patterns. Spring Creek's website framework embodies and integrates the two patterns described in this paper. But this framework also describes how the knowledge codified in the two patterns interacts in design implementation with further patterns. For example, another recurring problem for community organizations is that of preparing and disseminating newsletters (Merkel et al., 2004). This pattern is also evident in the website framework; the current newsletter and the newsletter archive are one click away from the homepage display of the organization's mission and strategic goals. The preparing and disseminating newsletters pattern (which we have not yet analyzed in the same detail as informal developmental learning or scaffolded documentation) highlights the need to organize members to contribute content and editorial assistance, and to streamline the formatting of newsletter content into email, webpages, and other formats (e.g., $p d f$ files). It suggests, for example, solution approaches like a wiki-based interface through which organizational stakeholders can add newsletter content without worrying about the details of formatting tags, and possibly pressing a button to generate the newsletter as a $p d f$ file styled according to a pre-defined template.

Yet another community-based learning design pattern might address the problem of managing diverse volunteers who have a variety of technical skills and vested interests. Within the website framework, this pattern implies the problem of who does what on the website while keeping organizational goals in mind. In our fieldwork, we have observed that community organizations want to micro-manage volunteers in relation to specific website tasks. In our work with Spring Creek (Farooq et al., 2007), it was noted that they did not want all volunteers to be able to update the entire website because it may be detrimental to the organization (volunteers' interest may not match organizational mission, volunteers may inadvertently delete vital content, etc). One possible solution that was discussed was to grant access rights to specific volunteers so they could change website content only for the sections to which they had privileges.

Frameworks, in the sense described above, help to develop a pattern-oriented programme for research and theory development in community-based learning in two complementary ways. On the one hand, they help to ground patterns more richly in experience. Frameworks make patterns easier to use by illustrating how a given pattern was applied in a particular kind of problem situation, and in the context of other patterns. Even though patterns themselves are rich and contextualized, they focus attention of analysts and designers on the context and dynamics of a single solution schema. However, solution patterns ultimately succeed or fail in a larger context of related problems and their forces, solutions, and contexts. In other words, patterns - ultimately-must be synthesized into implementations, and those implementations are both more comprehensive and more deeply contextualized. 
On the other hand, frameworks also provide rubrics for organizing and refining patterns as descriptions and as tools. Although patterns are often induced bottom-up from data, they can also be deduced by factoring a framework that instantiates several known patterns. As in our example of the Spring Creek website framework, two known patterns in this framework were factored out, helping us to identify two further patterns. Indeed, we think it is significant that Schuler's (2002) collection of community informatics patterns, and Alexander's (1979) original collection of urban design patterns are considered unwieldy by many practitioners; these two pattern languages are essentially long lists of patterns, albeit with some cross-referencing and examples, but without frameworks to integrate and operationalize them.

The key idea in Alexander's (1979) pattern language programme is to identify consequential invariants in existing design solutions, to ground them in the domain context and problems from which they arise, and to articulate their specific consequences for people and for human activity. This core idea is simple and powerful, and it has had extraordinary resonance through a wide variety of design communities. It is not a finished system; the idea of frameworks, for example, which itself is under development, seems essential to make pattern languages more than mere lists of knowledge nuggets. The pattern language programme seems particularly appropriate for design domains like community computing in which users and user organizations must participate in every aspect of design.

Acknowledgments A predecessor of this paper, discussing only the informal developmental learning pattern, under the more general name "community-based learning", appeared in the proceedings of the European Conference on Computer-Supported Cooperative Work (Carroll \& Farooq, 2005). We are grateful to the US National Science Foundation (grant numbers 0106552, 0342547, 0353101, 0429274) for supporting this research. We thank our colleagues and collaborators Mary Beth Rosson, Cecelia Merkel, Lu Xiao, and Craig Ganoe for helping us refine our ideas on patterns for community learning. Our research would not have been possible without the wonderful support of the various community groups we worked with as part of the Civic Nexus project.

\section{References}

Alexander, C. (1979). The timeless way of building. Oxford, UK: Oxford University Press.

Alexander, C., Ishikawa, S., Silverstein, M., Jacobson, M., Fiksdahl-King, I., \& Angel, S. (1977). A pattern language: Towns, buildings, construction. New York: Oxford University Press.

Avgeriou, P., Papasalouros, A., Retalis, S., \& Skordalakis, E. (2003). Towards a pattern language for learning management systems. Educational Technology \& Society, 6(2), 11-24.

Beamish, A. (1995). Communities on-line: Community-based computer networks, Masters Thesis, Department of Urban Studies and Planning, MIT.

Bellah, R., Madsen, R., Sullivan, W., Swindler, A., \& Tipton, S. (1986). Habits of the heart: Individualism and commitment in American life. Berkeley, CA: University of California Press.

Berlinger, L., \& Te'eni, D. (1999). Leader's attitudes and computer use in religious congregations. Non-profit Management and Leadership, 9(4), 399-411.

Bødker, S., Ehn, P., Sjögren, D., \& Sundblad, Y. (2000). Cooperative design-perspectives on 20 years with "the scandinavian IT design model. In Proceedings of the Nordic Conference on Human-Computer Interaction(NordiCHI 2000) (pp. 1-9). Stockholm, Sweden, October 22-24.

Carroll, J. M. (1998). Minimalism beyond the nurnberg funnel. Cambridge, MA: MIT.

Carroll, J. M. (2001). Community computing as human-computer interaction. Behaviour and Information Technology, 20(5), 307-314.

Carroll, J. M., Chin, G., Rosson, M. B., \& Neale, D. C. (2000). The development of cooperation: Five years of participatory design in the virtual school. In Proceedings of ACM Symposium on Designing Interactive Systems:DIS'2000 (pp. 239-251). New York: ACM.

Carroll, J. M., \& Farooq, U. (2005). Community-based learning: Design patterns and frameworks. In H. Gullersen, K. Schmidt, M. Beaudouin-Lafon, \& W. Mackay (Eds.), Proceedings of the 9th European 
conference on computer-supported cooperative work (pp. 307-324). Dordrecht, The Netherlands: Springer.

Carroll, J. M. \& Rosson, M. B. (2003). Design rationale as theory. In J.M. Carroll (Ed.), HCI models, theories and frameworks: Toward a multidisciplinary science (pp. 431-461). San Francisco, CA: Morgan-Kaufmann.

Carroll, J. M., Rosson, M. B., Dunlap, D. R., \& Isenhour, P. L. (2003). Frameworks for sharing knowledge: Toward a professional language for teaching practices. In Proceedings of the 36th Hawaii International Conference on System Sciences: HICSS-36. Washington DC: IEEE Computer Society.

Chung, E. S., Hong, J. I., Lin, J., Prabaker, M. K. Landay, J. A., \& Liu, A. L. (2004). Development and evaluation of emerging design patterns for ubiquitous computing. In Proceedings of the ACM Conference on Designing Interactive Systems: DIS 2004 (pp. 233-242) New York: ACM.

Clement, A., \& Van den Besselaar, P. (1993). A retrospective look at PD projects. Communications of the $A C M, 36(6), 29-37$.

Coleman, J. S. (1990). The foundations of social theory. Cambridge, MA: Harvard University Press.

Computer Research Association. (2003). Taulbee Survey., Last accessed March 1, 2005. Available at http:// www.cra.org/.

Corder, K. (2001). Acquiring new technology: Comparing nonprofit and public sector agencies. Administration and Society, 33(2), 194-219.

Dearden, A., \& Finlay, J. (2006). Pattern languages in HCI: A critical review. Human Computer Interaction, 21(1).

Deci, E. L., \& Ryan, R. M. (1985). Intrinsic motivation and self-determination in human behavior. New York: Plenum.

Dewey, J. (1916). Democracy in education. New York: Macmillan.

Dunlap, D. R., Neale, D. C., \& Carroll, J. M. (2000). Teacher collaboration in a networked community. Educational Technology and Society, 3(3), 442-454.

Eisinger, P. (2002). Organizational capacity and organizational effectiveness among street-level food assistance programs. Nonprofit and Voluntary Sector Quarterly, 31, 115-130.

Erickson, T. (2000). Lingua francas for design: Sacred places and pattern languages. In Proceedings of ACM Symposium on Designing Interactive Systems: DIS'2000 (pp. 357-368) New York: ACM.

Farooq, U., Ganoe, C. H., Xiao, L., Merkel, C. B., Rosson, M. B., \& Carroll, J. M. (2007). Supporting community-based learning: Case study of a geographical community organization designing their web site. In Behaviour and information technology: Special issue on computer-support for learning communities, vol. 26, no.1, pp. 5-21. London, UK: Taylor \& Francis.

Farooq, U., Merkel, C., Nash, H., Rosson, M. B., Carroll, J. M., \& Xiao, M. (2005). Participatory design as apprenticeship: Sustainable watershed management as a community computing application. In Proceedings of the 38th Hawaii International Conference on System Sciences: HICSS-38. Washington DC: IEEE Computer Society.

Farrington, C., \& Pine, E. (1997). Community memory: A case study in community communication. In P. Agre, \& D. Schuler (Eds.), Reinventing technology, rediscovering community: Critical explorations of computing as a social practice (pp. 219-228). Greenwich, CT: Albex.

Gamma, E., Helm, R., Johnson, R., \& Vlissides, J. (1994). Design patterns: elements of reusable objectoriented software. Reading, MA: Addison-Wesley.

Gerson, E. M., \& Star, S. L. (1986). Analyzing due process in the workplace. ACM Transactions on Office Information Systems, 4(3), 257-270.

Goodyear, P., Avgeriou, P., Baggetun, R., Bartoluzzi, S., Retalis, S., Ronteltap, F., et al. (2004). Towards a pattern language for networked learning. In S. Banks, P. Goodyear, V. Hodgson, C. Jones, V. Lally, D. McConnell, \& C. Steepless (Eds.) Networked Learning 2004 (pp. 449-455). Lancaster: Lancaster University.

Grobman, G. M. (2002). Pennsylvania nonprofit handbook: Everything you need to know to start and run your nonprofit organization. Harrisburg, PA: White Hat Communications.

Gross, T. (1999). Computer-supported community work: Old wine in new bottles? Workshop on broadening our understanding: Community networks and other forms of computer-supported cooperative work. In Proceedings of the European conference on computer supported cooperative work. Dordrecht, The Netherlands: Kluwer.

Guzdial, M., Rick, J., \& Kerimbaev, B. (2000). Recognizing and supporting roles in CSCW. In Proceedings of the conference on computer supported cooperative work (pp. 261-268). New York: ACM.

Johnson, R. E. (1997). Frameworks=(components and patterns). Communications of the ACM, 40(10), 39-42.

Kavanaugh, A., Reese, D. D., Carroll, J. M., \& Rosson, M. B. (2005). Weak ties in networked communities. The Information Society, 21(2), 119-131. 
Kensing, F., \& Blomberg, J. (1998). Participatory design: issues and concerns. Computer Supported Cooperative Work: The Journal of Collaborative Computing, 7(3-4), 167-185.

King, N. K. (2004). Social capital and nonprofit leaders. Nonprofit Management and Leadership, 14(4), 471-486.

Knowles, M. S. (1973). The adult learner: A neglected species. Houston, TX: Gulf Publishing Company, American Society for Training and Development.

Lave, J., \& Wenger, E. (1991). Situated learning: Legitimate peripheral participation. New York: Cambridge University Press.

Mcphail, B., Costantino, T., Bruckmann, D., Barclay, R., \& Clement, A. (1998). CAVEAT exemplar: Participatory design in a non-profit volunteer organisation. Computer Supported Cooperative Work (CSCW): The Journal of Collaborative Computing, 7(3-4), 223-243.

Merkel, C. B., Clitherow, M., Farooq, U., Xiao, L., Ganoe, G. H., Carroll, J. M., et al. (2005). Sustaining computer use and learning in community computing contexts: Making technology part of "who they are and what they do". The Journal of Community Informatics [Online], 1(2), 134-150. Available at: http:// ci-journal.net/viewarticle.php?id=53\&layout $=$ html.

Merkel, C. B., Xiao, L., Farooq, U., Ganoe, C. H., Lee, R., Carroll, J. M., et al. (2004). Participatory design in community computing contexts: tales from the field. In Proceedings of the 8th conference on participatory design: Artful integration: Interweaving media, materials and practices (pp. 1-10). New York: ACM.

Putnam, R. (2000). Bowling alone: The collapse and revival of American community. New York: Simon \& Schuster.

Rainie, L., \& Horrigan, J. (2005). A decade of adoption: How the Internet has woven itself into American life. Trends 2005, Pew Research Center. Last accessed March 1, 2005; Available at: http://pewresearch.org.

Rheingold, H. (1993). The virtual community: Homesteading on the electronic frontier. Reading, MA: Addison-Wesley.

Rogers, E. M., Collins-Jarvis, L., \& Schmitz, J. (1994). The PEN project in santa monica: Interactive communication, equality, and political action. Journal of the American Society for Information Science, 45(6), 401-410.

Ryan, R. M., \& Deci, E. L. (2000). Self-determination theory and the facilitation of intrinsic motivation, social development, and well-being. American Psychologist, 55, 68-78.

Sachs, P. (1995). Transforming work: collaboration, learning, and design. Communications of the ACM, 38 (9), 36-44.

Salamon, L. M., Sokolowski, S. W., \& List, R. (2003). Johns Hopkins comparative nonprofit sector pproject: Global civil society at-a-glance: Major findings of the John Hopkins comparative nonprofit sector project. Baltimore, MD: John Hopkins Press.

Saponas, T. S., Prabaker, M. K., Abowd, G. D. \& Landay, J. A. (2006). The impact of pre-patterns on the design of digital home applications. In Proceedings of the ACM Conference on Designing Interactive Systems: DIS 2006 (pp. 189-198). New York: ACM.

Schuler, D. (2002). A pattern language for living communication. In Proceedings of the 6th conference on participatory design (pp. 434-436). Palo Alto, CA: CPSR.

Techsoup (2005). Technology planning. Accessed March 2, 2005; Available at: http://www.techsoup.com/ howto/articles.cfm?topicid $=11 \&$ topic $=$ Technology $\% 20$ Planning.

Trigg, R. H., \& Bødker, S. (1994). From implementation to design: tailoring and the emergence of systematization in CSCW. In Proceedings of the conference on computer supported cooperative work (pp. 45-54). New York: ACM.

Uncapher, W. (1999). Electronic homesteading on the rural frontier: Big Sky Telegraph and its community. In M. Smith, \& P. Kollock (Eds.), Communities in cyberspace (pp. 264-289). Oxford, UK: Routledge.

Vygotsky, L. S. (1978). Mind and society: The development of higher mental processes, Cambridge, MA: Harvard University Press.

Wellman, B. (1982). Studying personal communities. In P. Marsden \& N. Lin (Eds.), Social networks and social structure (pp. 61-80). Beverly Hills, CA: Sage.

Yin, R. K. (2003). Case study research: Design and methods. Thousand Oaks, CA: Sage. 